\title{
Insight into the secondary imbibition rate of concrete and its relationship with curing time
}

\author{
Natalia Alderete ${ }^{1}$, Yury Villagran Zaccardi ${ }^{1}$, Nele De Belie $^{1}$ \\ ${ }^{1}$ Magnel-Vandepitte Laboratory for Structural Engineering and Building Materials, Ghent University, Gent, Belgium
}

Received: 24 July 2020 / Accepted: 30 November 2020 / Published online: 22 December 2020

(C) The Author(s) 2020. This article is published with open access and licensed under a Creative Commons Attribution 4.0 International License.

\begin{abstract}
Long-term capillary imbibition in cementitious materials is relevant to describe their durable behaviour. After several weeks, when capillary rise is no longer progressing, a distinguished change in the slope (from the mass gain - fourth root of time relation) is noticed. Primary and secondary imbibition rates (PIR and SIR, respectively) can be obtained from such behaviour. Contrary to the widely investigated PIR, usually defined as the capillary absorption rate, the SIR has been scarcely examined. To evaluate this unexplored process, we contrasted values of SIR and porosity. Moreover, using statistical inference we evaluated the evolution of the SIR of concrete mixes with different composition and curing age. This paper presents the effect of curing on the SIR and the relation between porosity changes and SIR. Despite the decrease in capillary and intrudable porosity, SIR increases with curing time having an opposite evolution than the PIR. Another interesting finding is this increase is irrespective of mix composition (including cement type, w/b ratio, aggregate amount, presence of SCMs). Results show that the PIR and SIR are influenced by different mechanisms with dissimilar correlations with porosity and curing time.
\end{abstract}

Keywords: Secondary sorptivity; Capillary imbibition; Long-term water ingress; Durability

\section{Introduction}

Concrete is a sensitive material concerning moisture and water transport. Many changes occur in concrete as free water content fluctuates. Whereas the effect of moisture content on volumetric stability is extensively addressed in the literature, the effects of changes in the pore structure due to the interaction with the medium on the rate of transport processes is still a matter of research. The microstructural complexity of cementitious materials has challenged researchers for decades in search for a comprehensive model for the interaction between the matrix and free water. The study of cementitious materials as changing matrix during water transport is insufficiently reported in the literature. Even less reports on results of long-term transport experiments analysed considering the evolution in the pore structure can be found. These aspects are fundamental for an accurate description and modelling of cementitious materials concerning transport properties. As water is a carrying medium for many detrimental substances that eventually penetrate in concrete, not addressing the anomalies of water transport in concrete limits the efficiency of current models in the literature.

When testing capillary imbibition, some researchers [1-6] have reported further water uptake even after the water front has covered the total height of samples. This secondary progression of water ingress develops at a much slower rate than the short-term capillary imbibition, and it can be related to a derived process that involves the finest range of pores. Other researchers suggest however that entrapped air [7] or the use of the fractal theory [8] can describe such long-term behaviour. Hall and Hamilton [7], state that during the secondary imbibition period, trapped air dissolves in the water and its volume is replaced by water ingress into the material. As such, they propose that the rate of the secondary imbibition period is controlled by the excess pressure of the trapped air. The fractal approach proposed by Cai et al [8], although interesting, seems to be valid only for a short period of time and it does not allow to describe the change from the primary to the secondary period. In previous research [9], a model has been presented to describe the long-term behaviour during capillary imbibition. Basically, the water ingress process develops in three main stages: the primary period, followed by a transition period, and finally the secondary period. The primary period is dominated by capillary forces that are responsible for the water movement up to the top of the sample. Normally the information from this period is used to calculate the sorptivity index or primary imbibition rate (PIR), and it is addressed by all standard tests on sorptivity. The variation from the primary to the secondary stage (transition) corresponds to a variation in the slope of the water uptake curve. This change is not abrupt and the main

\footnotetext{
* Corresponding author: Natalia Alderete, Email: nataliamariel.alderete@ugent.be
} 
reason for it seems to be the gradual changing in the main driving force: from capillarity to diffusion of water through the pore network. The secondary period can be noticed only after the main water front has reached the top of the sample (hence no capillary potential available). The secondary imbibition rate (SIR) is much lower than the primary rate, probably due to a slow diffusion-controlled transport. Such description of the water ingress in stages is useful to analyse long-term exposure to capillary imbibition and it has been applied to several concrete mixes in [9]. To deepen in these descriptions and to have an overview of the phenomenon, we need quantitative tools that contribute to rationally separate the different periods. Particularly, the second imbibition period as described in [9] has not been deeply studied yet and it is the focus of this research. The secondary imbibition progressing linearly with the fourth root of time needs further description, hence we evaluate here the effect of curing period on the evolution of the SIR.

Only short-term capillary imbibition experiments are indicated in standards. We may believe that the approach from ASTM C1585 [10] goes further than other standards, as it divides water ingress rate into initial (slope of the curve during the first $6 \mathrm{~h}$ ) and secondary (slope of the same curve between 1 and 7 days) rates. This secondary coefficient is on its own not always valid, as the standard requires the verification of linearity with the square root of time for the segment $\left(R^{2}>0.98\right)$. As mentioned by Villagran et al. [11], 7 days of testing should still be considered a short test period, as capillary forces dominate the process during the whole exposure time. In many cases this short period is not even able to provide sufficient information for the modelling of capillary absorption in the bulk material [12]. With the same phenomenon dominating the whole test duration, the division seems to lack a solid physical support. Figure 1 displays data from [13] plotted against the fourth root of time (instead of the conventional square root of time) of concrete samples that were measured following the ASTM standard, except that measurements were continued for up to 368 hours. The periods that would correspond to the primary and secondary period as defined by the standard are marked with ellipses. It is clear that there is no difference in the slope when the fourth root of time is used. In fact, the segmented analysis of ASTM C 1585 is only aimed to disguise the lack of linearity of the mass gain with the square root of time. This lack of linearity is caused by the C-S-H swelling coupled with the restrictions of the system. The restrained deformations are translated into a variable porosity that progressively hinders the water flow leading to the fourth root of time approach. Although the use of a single value for the exponent for the time during the primary imbibition may require additional fundamental research, it offers a very practical and sufficiently precise description of the capillary imbibition. Moreover, measurements of the mentioned deformations presented in [14] support the main hypothesis of the fourth root of time approach. Most deformations were registered during the primary period hence deeper look into the secondary imbibition period is needed.

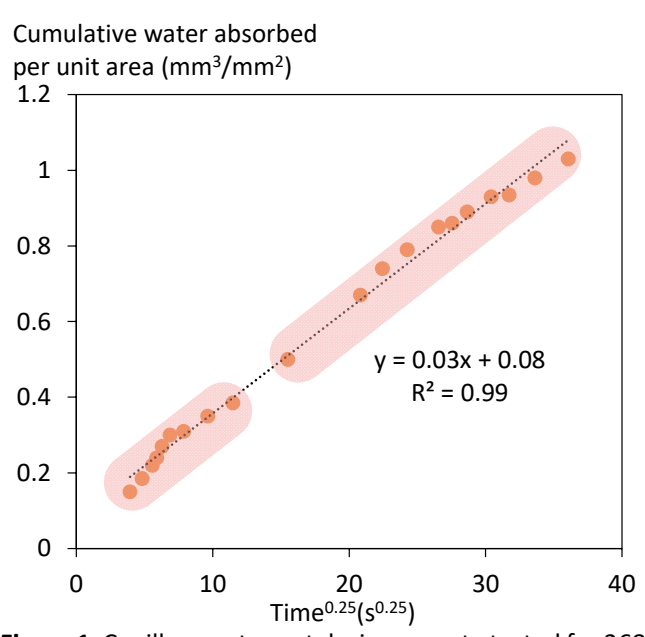

Figure 1. Capillary water uptake in concrete tested for 368 hours, data from [13].

The utility of the description of the long-term capillary water uptake is still to be further explored. As pointed out by Hall [7], the value of the SIR as a material property and its relation to other transport properties remains to be established. The importance of the long-term phenomenon has been quite neglected, as the data from literature of capillary imbibition tests in concrete lasting more than 7 days is very limited. A deeper look into the unexplored SIR and its relation to other concrete properties is needed. Particularly, porosity properties seem relevant to evaluate the relation between changes in pore structure with time and the SIR.

One of the main aspects of evolution of porosity with time comprises the effect of curing time on the SIR. This aspect is particularly relevant for many practical applications in structures exposed for long time to a source of moisture. It is known that the PIR decreases with curing age due to a reduction in the porosity of the matrix with further hydration. Whether this is also the case for the SIR remains to be investigated. Differences may be expected in correspondence with the different pore size ranges that are involved in the dominant transport mechanisms during the primary and secondary imbibition.

In this research we analyse the relation between SIR and porosity evaluated by water accessible porosity (under vacuum) and intrudable porosity (by means of mercury intrusion porosimetry, MIP) of several concrete mixes. We also evaluated the evolution of the SIR when testing such mixes at different ages to determine the effect of curing time.

\section{Materials and methods}

Long-term capillary imbibition experiments (up to 7 months of exposure) were performed in 4 concrete mixes cured for 28 and 91 days. Their mix composition is described in Table 1. Note that PIA stands for processed incineration ashes (i. e., municipal solid waste incineration ashes after special treatment designed to make them suitable for their use in concrete). Further detailed information about the PIA can be found in [15-17].

For the statistical analysis presented in this research, the data from Mixes 1-4 and 7 other concrete mixes (OPC, SB20, SB40, 
SB60, FA20, FA30 and FA40) were used. These mixes have the same water to binder ratio but different binder type. The first one contained only Portland cement, the second to the fourth contained increasing replacement ratios by ground granulated blast furnace slag (SB), and the fifth to the seventh mixes contained increasing replacement ratios by fly ash (FA). Their mix composition is described in Table 1. More details about materials and mix composition can be found in [9].

All samples, from concrete mixes described in [9] and the ones from Mixes 1-4, were tested after 28 and 91 days of curing in a conditioned room at $(20 \pm 1)^{\circ} \mathrm{C}$ and $(95 \pm 5) \% \mathrm{RH}$. For the capillary imbibition experiments, specimens were laterally water-proofed cylinders of $50 \mathrm{~mm}$ height and 100 $\mathrm{mm}$ in diameter, sawed from the sector between 30 and 80 $\mathrm{mm}$ from the base of cylinders of $200 \mathrm{~mm}$ height and $100 \mathrm{~mm}$ in diameter. The top and bottom faces of the samples remained uncovered. Preconditioning of samples consisted in $72 \mathrm{~h}$ immersion in water and then drying in an oven at $50{ }^{\circ} \mathrm{C}$ until the mass decrease was lower than a mass fraction of 0.1 $\%$ in a $24 \mathrm{~h}$ period. The capillary imbibition test consisted in putting the samples in contact with water, immersed $(3 \pm 1)$ $\mathrm{mm}$, and regularly weighing the mass increase (after $0.5,1,2$, $3,4,5,6,24 \mathrm{~h}$ of contact with water, then every $24 \mathrm{~h}$ during the first week, and afterwards every 1 week until the end of the experiment). A lid on top of the water container was used to avoid evaporation. The water level was kept constant during the whole testing period by regularly checking the immersion depth. The time when the water front reached the top of the samples was considered to be indicative of the end of the primary imbibition period (thus the primary imbibition rate was calculated as slope of the fitting line between the first measurement and the end of the primary imbibition period as just described). After this time, the transition period begins and when the water ingress rate is stabilised the secondary imbibition slope can be calculated. These longterm capillary imbibition tests were performed for at least 15 weeks.

Considering the variability of test results, we further analysed the curing effect by means of hypothesis tests. In this manner, comparisons between imbibition rates at different ages are based on a rational basis. The advantage provided by hypothesis tests is that it is possible to determine the statistical relevance of the hypothesis with a certain confidence level.

To identify the relation between the SIR and other concrete properties, we also evaluated open porosity (OP) and intrudable porosity at 28 and 91 days.

Cylinders of $100 \mathrm{~mm}$ in diameter and $200 \mathrm{~mm}$ in height from mixes OPC, SB20, SB40, SB60, FA20, FA30 and FA40 were demoulded 1 day after casting, and cured in a climate room at a temperature of $(20 \pm 2){ }^{\circ} \mathrm{C}$ and $(95 \pm 5) \% \mathrm{RH}$ until 28 and 91 days of age. Five samples from the lowest $54 \mathrm{~mm}$ were cut from different cylinders and used for testing. Those slices were subjected to vacuum for $2 \mathrm{~h}$ and then water was drawn into the vacuum chamber until the samples were fully immersed. After $24 \mathrm{~h}$ samples were removed and weighed, this weight was denoted as saturated mass in air (msa). The samples were also weighed in water, and this weight was denoted as saturated mass in water (msw). Then, samples were subjected to drying in an oven at $105^{\circ} \mathrm{C}$ until the change in mass was lower than $0.1 \%$ in a $24 \mathrm{~h}$ period, and denoted as dry mass (md). The OP was calculated as (msa-md)/(msa$\mathrm{msw}$ ).

Table 1. Composition of the studied concrete mixes.

\begin{tabular}{|c|c|c|c|c|c|c|c|c|c|c|c|}
\hline Material & Mix 1 & Mix 2 & Mix 3 & Mix 4 & OPC & SB20 & SB40 & SB60 & FA20 & FA30 & FA40 \\
\hline Sand $0 / 1\left(\mathrm{~kg} / \mathrm{m}^{3}\right)$ & 271 & 271 & 271 & 271 & - & - & - & - & - & - & - \\
\hline Sand $0 / 4\left(\mathrm{~kg} / \mathrm{m}^{3}\right)$ & 541 & 541 & 541 & 542 & 865 & 860 & 860 & 860 & 860 & 860 & 855 \\
\hline Gravel $2 / 8\left(\mathrm{~kg} / \mathrm{m}^{3}\right)$ & - & - & - & - & 500 & 497 & 495 & 493 & 497 & 493 & 490 \\
\hline $\begin{array}{ll}\begin{array}{l}\text { Gravel } \\
\left(\mathrm{kg} / \mathrm{m}^{3}\right)\end{array} & 8 / 16 \\
\end{array}$ & - & - & - & - & 540 & 535 & 535 & 535 & 535 & 535 & 530 \\
\hline $\begin{array}{ll}\begin{array}{l}\text { Gravel } \\
\left(\mathrm{kg} / \mathrm{m}^{3}\right)\end{array} & 4 / 16 \\
\end{array}$ & 997 & 997 & 997 & 999 & - & - & - & - & - & - & - \\
\hline \begin{tabular}{l|r} 
CEM & \multicolumn{1}{c}{42.5} \\
N/SB $/$ FA & $\left(\mathrm{kg} / \mathrm{m}^{3}\right)$ \\
\end{tabular} & - & - & - & - & $\begin{array}{l}342 / 0 / \\
0\end{array}$ & $\begin{array}{l}274 / 68 \\
10\end{array}$ & $\begin{array}{l}205 / 13 \\
7 / 0\end{array}$ & $\begin{array}{l}137 / 20 \\
5 / 0\end{array}$ & $\begin{array}{l}274 / 0 / \\
68\end{array}$ & $\begin{array}{l}239 / 0 / \\
103\end{array}$ & $\begin{array}{l}205 / 0 / \\
137\end{array}$ \\
\hline $\begin{array}{lll}\begin{array}{l}\text { CEM I } \\
\left(\mathrm{kg} / \mathrm{m}^{3}\right)\end{array} & 52.5 & \mathrm{~N} \\
\end{array}$ & 360 & - & 270 & - & - & - & - & - & - & - & - \\
\hline $\begin{array}{l}\text { CEM II B-V } 32.5 \text { R } \\
\left(\mathrm{kg} / \mathrm{m}^{3}\right)\end{array}$ & - & 360 & - & - & - & - & - & - & - & - & - \\
\hline $\begin{array}{llll}\text { CEM I } & 52.5 & \mathrm{R} \\
\left(\mathrm{kg} / \mathrm{m}^{3}\right) & & \\
\end{array}$ & - & - & - & 296 & - & - & - & - & - & - & - \\
\hline $\operatorname{PIA}\left(\mathrm{kg} / \mathrm{m}^{3}\right)$ & - & - & 90 & 74 & - & - & - & - & - & - & - \\
\hline Water $\left(\mathrm{kg} / \mathrm{m}^{3}\right)$ & 173 & 174 & 172 & 167 & 154 & 154 & & & & & \\
\hline $\begin{array}{l}\text { Plasticiser (\% wt. } \\
\text { of binder) }\end{array}$ & 1.8 & 1.8 & 2.7 & 3.9 & $*$ & $*$ & * & * & * & * & * \\
\hline
\end{tabular}

* The product information indicated an optimal dosage between $4.5 \mathrm{ml}$ and $13 \mathrm{ml}$ per kg of cement. An intermediate dosage was chosen. 
The samples for MIP were obtained from the concrete mixes: SB20, SB40, SB60, FA20, FA30 and FA40. Sample volume was approximately $125 \mathrm{~mm}^{3}$, obtained from the core of one cylinder per mix. Microstructural damage during preconditioning was minimized by first drying samples at $40^{\circ} \mathrm{C}$ for $24 \mathrm{~h}$, and then vacuum-drying them at $(20 \pm 2)^{\circ} \mathrm{C}$ for two weeks at 0.1 bar $[18,19]$. The maximum applied pressure during MIP was $200 \mathrm{MPa}$ in order to avoid cracking induced by the pressure [20]. Measurements were corrected with a blank to disregard differential mercury compression. The surface tension and contact angle considered for these computations were $0.482 \mathrm{~N} / \mathrm{m}$ and $142^{\circ}$ [21], respectively.

\section{Results}

Results from long-term capillary imbibition tests of Mixes 1-4 are shown in Figure 2-Figure 5. Similar graphs for the other mixes can be found in [9]. This data illustrates how the primary imbibition rate is progressively slowed down after the capillary rise covered the total height of samples. The new results confirm the previous description of the long-term capillary water ingress as divided in three periods: primary, transition and secondary [9]. Linearity with the fourth root of time is high in all cases for both the primary and secondary periods. The values between parenthesis indicate the $95 \%$ confidence interval for the PIR and SIR values.

Imbibition experiments monitored by neutron radiography for 4 weeks [22] show a similar behaviour as described here. Although authors calculated the primary and secondary sorptivity based on the ASTM C 1585-14, the shape of the water ingress visualised with radiographs display the lack of linearity with the square root of time. Furthermore, their calculations show that the filling of the matrix pores occurs when there is a clear decrease in the slope (around 11 days for the tested mixes, which it is even after the secondary period as calculated per ASTM).

Results for PIR, SIR, OP and MIP intrudable porosity are summarised in Figure 6. Points in the figure represent the PIR and SIR at 28 and 91 days (from mixes OPC, SB20/40/60, FA20/30/40) (horizontal axis); and OP and MIP intrudable porosity at 28 and 91 days from mixes SB20/40/60, FA20/30/40 (left and right vertical axis, respectively). We can observe that, as expected, curing time decreases porosity (both intrudable and water accessible porosity). Accordingly, the PIR of all concrete mixes reduces with increasing curing time. However, values of the SIR seem to increase with time, in spite of the decrease in porosity. The general trend of SIR increasing with time regardless of the decrease in OP and intrudable porosity has quite some variability and it is not possible to elaborate a solid statement without further analysis. To obtain more conclusive information, hypothesis tests were performed and are discussed in the following section.
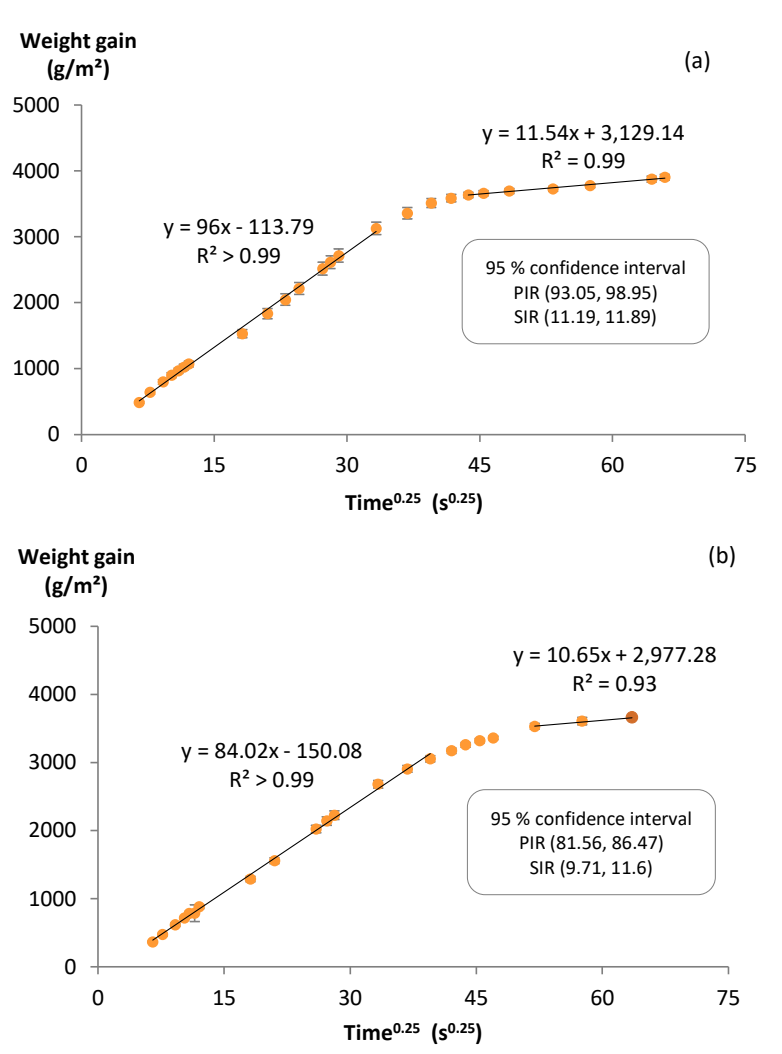

Figure 2. Capillary imbibition rate of Mix 1 at 28 (a) and 91 (b) days of age. The $95 \%$ confidence intervals of the corresponding PIR and the SIR are given between parenthesis.

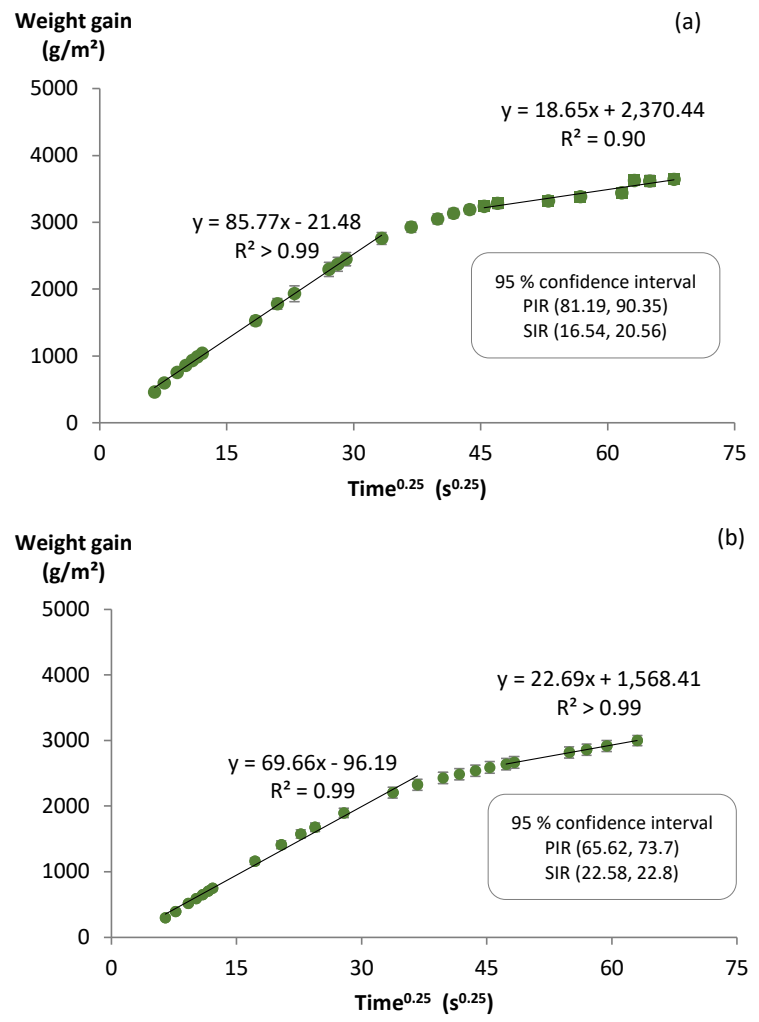

Figure 3. Capillary imbibition rate of Mix 2 at 28 (a) and 91 (b) days of age. The $95 \%$ confidence intervals of the corresponding PIR and the SIR are given between parenthesis. 

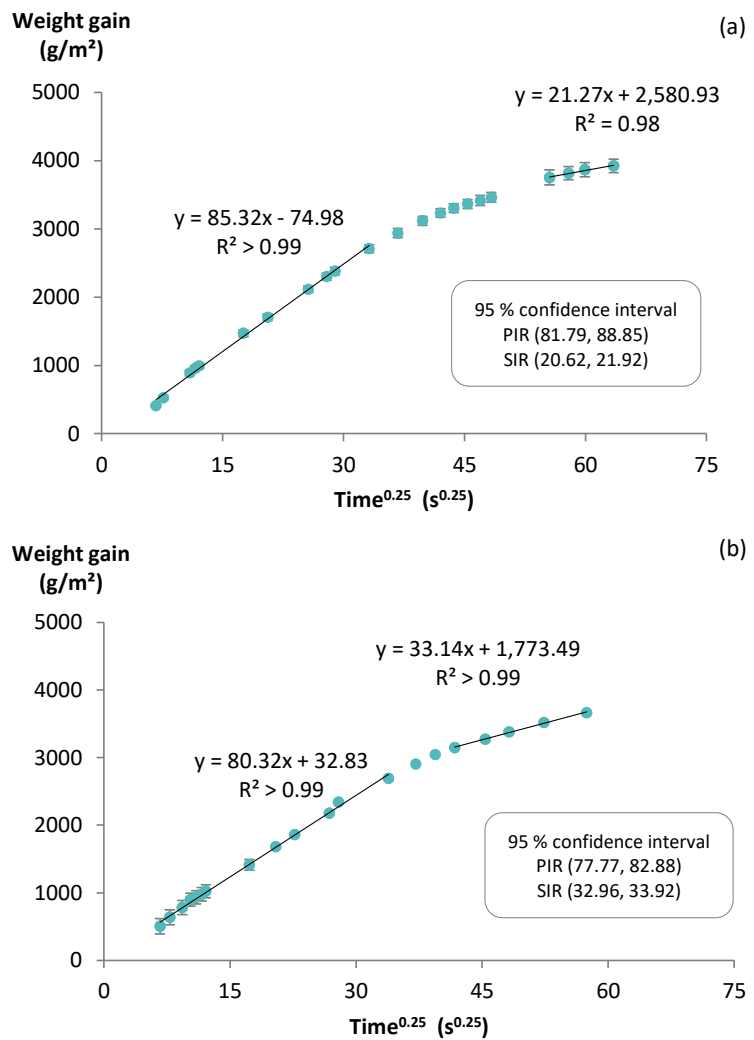

Figure 4. Capillary imbibition rate of Mix 3 at 28 (a) and 91 (b) days of age. The $95 \%$ confidence intervals of the corresponding PIR and the $\mathrm{SIR}$ are given between parenthesis.
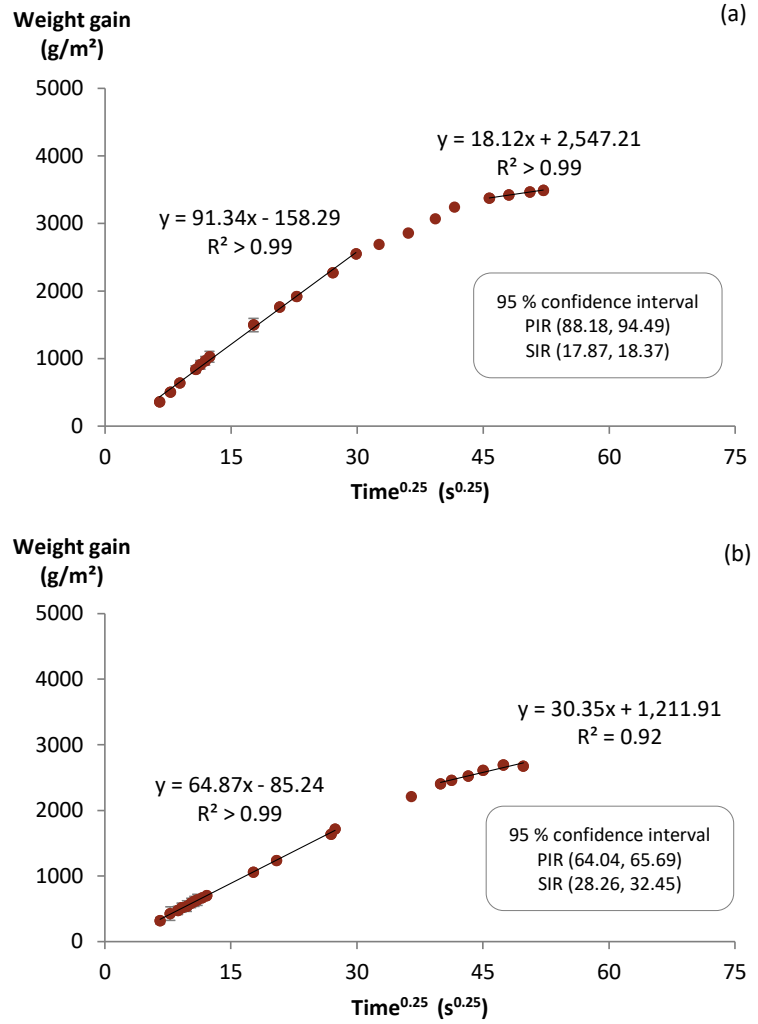

Figure 5. Capillary imbibition rate of Mix 4 at 28 (a) and 91 (b) days of age. The $95 \%$ confidence intervals of the corresponding PIR and the SIR are given between parenthesis.

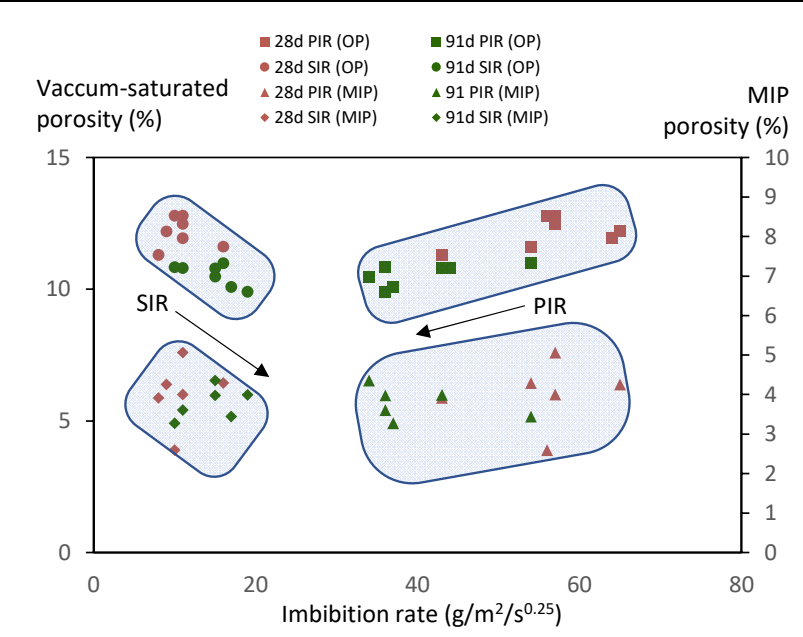

Figure 6. Relation between open OP and PIR and SIR at 28 and 91 days (from mixes OPC, SB20/40/60, FA20/30/40); and between MIP intrudable porosity and PIR and SIR at 28 and 91 days (from mixes SB20/40/60, FA20/30/40).

The values of the relative accessible porosity occupied by water entering the sample at the end of the primary capillary imbibition period in Mixes 1-4 after 28 and 91 days of curing are shown in Figure 7. The relative volume corresponds to the average of the (vacuum-saturated) porosity filled by water at the end of the primary imbibition period (error bars indicate the standard deviation, $n=5$ ). The moisture content reached at the end of the primary period was calculated considering the fourth root of time approach. The total porosity is around $50 \%$ filled, which indicates that almost all capillary pores are filled at the end of the primary imbibition period.

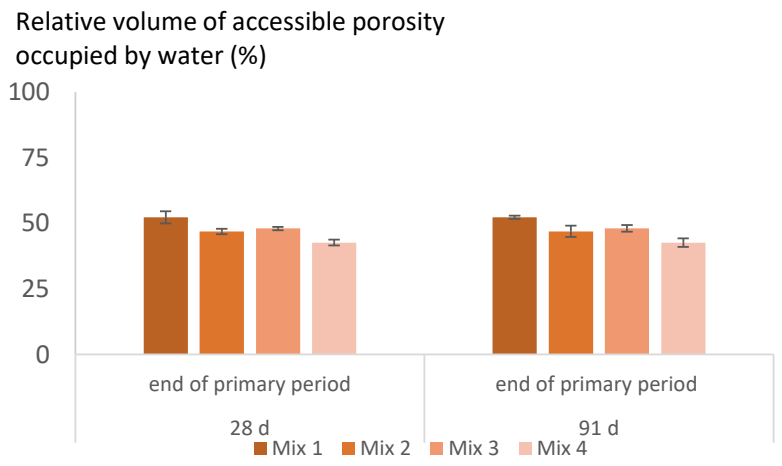

Figure 7. Relative volume of occupied porosity by the water in the sample at the end of the primary imbibition period in Mixes 1-4 cured for 28 and 91 days.

\section{Discussion}

Normally, values of the PIR and the SIR are very different, being the latter the smallest one. This much lower water ingress during the secondary imbibition period is due to the change in the main controlling force from the primary to the secondary period and the difference in the pore size involved. When testing samples with different curing time, this difference in the rate values remains but curing age does not seem to affect PIR and SIR on the same way. On the one hand, the difference between the values of PIR at 28 and at 91 days is rather noticeable. As it is well-known, curing influences 
pore structure and makes concrete less porous. Therefore, the PIR is lower at later ages. However, when comparing the SIR at 28 and 91 days the trend is not the same. In other words, it seems that the effect of curing time is depicted by an increased SIR value.

Results from Figure 6 indicate that SIR is higher at 91 days than at 28 days irrespective of the reduction in porosity. It seems that SIR does not decrease with time, or it even increases with time. Therefore, it is relevant to make a statistical analysis to objectively determine the evolution of the SIR with time. For that purpose, the SIR values of each tested sample $(n=5)$ from the 11 concrete mixes were analysed with statistical hypothesis tests (t-tests) considering matched-pairs (28 and 91 days) and independent samples respectively.

The test of matched-pairs was performed to address the effect of curing time from 28 to $91 \mathrm{~d}$ as a treatment for each concrete mix. In this case, the potential influence of the particular amount of SCM replacement or type of SCM on the SIR coefficient is disregarded and the analysis is focused on the effect of age. First we considered the hypothesis that the mean of the difference between SIR at $28 \mathrm{~d}$ and SIR at $91 \mathrm{~d}$ is zero, i.e. the SIR does not change with time. An unilateral test is performed, where the alternative hypothesis would indicate that the mean of the difference is lower than zero, i.e. SIR is higher at $91 \mathrm{~d}$ than at $28 \mathrm{~d}$. This can be expressed as HO: $\mu \mathrm{d}=0$, with $\mathrm{H} 1: \mu \mathrm{d}<0$. A $95 \%$ confidence level $(\alpha=0.05)$ was chosen for the test.

The mean difference and the obtained $p$-value are shown in Table 2. The mean value for $\mu d$ is negative. The $p$-value $(0.0022<0.05)$ indicates that there is statistically significant evidence at $\alpha=0.05$ to reject the null hypothesis. This directs us to reliably state that the SIR increases from $28 \mathrm{~d}$ to $91 \mathrm{~d}$ in the studied concrete mixes.

Table 2. Data of the difference in means of the SIR in concrete.

\begin{tabular}{|l|l|}
\hline & $\begin{array}{l}\text { Matched-pairs t-test of SIR } \\
\text { concrete mixes } \\
\text { at 28 d and 91 d }\end{array}$ \\
\hline Mean $\left(\mathrm{mg} / \mathrm{mm}^{2} / \mathrm{s}^{0.25}\right) \cdot 10^{3}$ & -4.93 \\
\hline $\begin{array}{l}\text { Standard deviation } \\
\left(\mathrm{mg} / \mathrm{mm}^{2} / \mathrm{s}^{0.25}\right) \cdot 10^{3}\end{array}$ & 4.48 \\
\hline Sample size & 11 \\
\hline p-value & 0.0022 \\
\hline
\end{tabular}

Now, it is also possible to consider the whole set of samples and evaluate the difference between means at $28 \mathrm{~d}$ and $91 \mathrm{~d}$ of the SIR. In such manner, it is of interest to compare the two independent groups (SIR at $28 \mathrm{~d}$ and SIR at $91 \mathrm{~d}$ ) with respect to their mean values. For that, rather than generating an estimate of the difference $(\mu \mathrm{d})$, it is possible to test whether the observed difference between $\mu 28$ and $\mu 91$ is statistically significant or not. If conclusive, it would allow to state that the influence of curing age is noticeable in spite of the other factors affecting the variability of the data.

From the results in Table 3 it is interesting to see how even when comparing the whole set of concrete mixes as independent samples, still the null hypothesis $(\mathrm{HO}: \mu \mathrm{d}=0)$ is rejected. This indicates that SIR values at $28 \mathrm{~d}$ and at $91 \mathrm{~d}$ are statistically not equal. The alternative hypothesis $(\mathrm{H} 1: \mu \mathrm{d}<$ 0) stipulating that SIR increases with time can therefore be accepted.

Furthermore, we also carried out an ANOVA to investigate the different main and interaction effects (an interaction effect means that the effect of one factor depends on the level of another factor). When comparing the relative importance of the main effects (Age, type of SCM and Replacement level), pvalues were found to be lower than 0.05 in all cases, which indicates that they are all important. Regarding the interactions, the following ones were analysed: Age*SCMs, Age*Replacement, SCMs*Replacement and Age*SCMs*Replacement. In this sense, the effect of age on the SIR is significantly different for different SCMs (thus the age effect depends on the type of SCM). This is probably related to the effect of curing on the $\mathrm{C}-\mathrm{S}-\mathrm{H}$ content of the mixes with different $\mathrm{SCMs}$, as curing for longer periods will result in different $\mathrm{C}-\mathrm{S}-\mathrm{H}$ content when different SCMs are used. Presumably, the evolution of SIR with time may be reflecting the increase in C-S-H content with time. Further research to confirm this hypothesis is necessary. Furthermore, the effect of age on the SIR does not significantly depend on the replacement level (and vice versa) and the effect of replacement level on SIR is similar for all SCMs (and vice versa). When including the main and interaction effects in our model, we could explain $83 \%$ of the variability in the SIR data. This value seems acceptable for concrete experimental results.

As mentioned before, there are only few data in literature where long-term capillary imbibition in concrete is evaluated. Even less literature is available in which long-term capillary imbibition is performed in samples with different curing ages. To the knowledge of the authors, only Henkensiefken et al. [6], attempted to evaluate the secondary capillary imbibition rate as defined by ASTM C 1585 for mixes with different curing ages $(1,7,28$ and 90 days). Yet, results were only obtained up to 8 days of exposure, and these differences in slope do not describe the physics of the actual SIR resulting from a process different from capillarity.

Table 3. Results from a t-test considering independent samples.

\begin{tabular}{|l|l|l|}
\hline & $\begin{array}{l}\text { SIR in concrete mixes at } \\
28 \mathrm{~d}\end{array}$ & $\begin{array}{l}\text { SIR in concrete mixes at } \\
91 \mathrm{~d}\end{array}$ \\
\hline Mean $\left(\mathrm{mg} / \mathrm{mm}^{2} / \mathrm{s}^{0.25}\right) \cdot 10^{3}$ & 13.2 & 18.2 \\
\hline Standard deviation $\left(\mathrm{mg} / \mathrm{mm}^{2} / \mathrm{s}^{0.25}\right) \cdot 10^{3}$ & 4.5 & 7.7 \\
\hline Sample size & 11 & 11 \\
\hline $\mathrm{p}$-value & 0.0406 & \\
\hline
\end{tabular}


Similarly, Ghasemzadeh and Pour-Ghaz [23] studied the 'longterm' capillary imbibition in concrete subjected to different levels of damage but again only until 7 days. Therefore, the secondary imbibition period described in the present research does not compare to data in $[6,23]$ that align when plotted against the fourth root of time (same as the data from [13], see Figure 1). In the present study the SIR was calculated after the water front reached the top of the samples, which normally took between 1 and 3 weeks. Then, only when the sample height was covered, the main mechanism stops being capillarity clearly reflecting in the decrease in the water uptake rate.

Results obtained from the 11 studied concrete mixes indicate that the SIR increases with curing age. This finding is rather unexpected. The SIR does not follow the pattern of PIR (or most transport properties for that matter) as generally indexes are reduced with time. One possible explanation is that the SIR is mainly controlled by a parameter different from porosity.

Assuming that during the secondary period the main driving force is diffusion, and that the ingress is influenced by the C$\mathrm{S}-\mathrm{H}$ paths, it is likely that the increase in the SIR coefficient is connected to a greater amount of C-S-H in the samples. This agrees with the link between the secondary period and the $\mathrm{C}$ $\mathrm{S}-\mathrm{H}$ content which is naturally higher at later ages. The decoupling of the SIR from the PIR is a fundamental aspect that deserves further experimental analysis. Such advances may help in better connecting the interaction of the microstructure of concrete with the medium and the durable performance of concrete structures.

\section{Conclusions}

Long-term experiments of water transport in cementitious materials can provide complementary information for the description of the microstructure of concrete. In this research we evaluated the relationship between porosity (by means of water saturation under vacuum -OP- and MIP) and the secondary imbibition rate (SIR). The general trend indicates that, regardless of the decrease in OP and MIP intrudable porosity, SIR increases with time. Based on the hypothesis test made with 11 concrete mixes and $95 \%$ level of confidence, the SIR increases when samples are tested at 91 days in comparison to samples tested at 28 days of curing.

The findings can be summarised as follows:

(1) SIR increases with curing time in spite of the decrease in the porosity of the cementitious matrix. Such finding is of particular interest in regards to the long-term evaluation of concrete structures as obtaining a larger SIR can be an indication of a lower porosity,

(2) this increase is irrespective of mix composition (including cement type, $w / b$ ratio, aggregate amount, presence of SCMs),

(3) considering the interaction effects: Age*SCMs, Age*Replacement, SCMs*Replacement and Age*SCMs*Replacement, the most important conclusion to point out is that the effect of age on the SIR is significantly different for different SCMs (thus the age effect depends on the type of SCM),

(4) the behaviour of the SIR is surprisingly the opposite of the PIR (which decreases with time), this can be possibly explained by increase in C-S-H content, as this secondary period is probably associated to diffusion in the C-S-H sheets. This is still to be further confirmed by future research.

The present research confirms that the PIR and SIR have dissimilar correlations with the porosity and curing time of concrete. To understand the moisture dynamics in long-term exposure conditions, further research is needed to evaluate the relation between the SIR and other properties and features of cementitious materials, particularly its connection with the $\mathrm{C}-\mathrm{S}-\mathrm{H}$ content in concrete.

\section{Acknowledgements}

Natalia Alderete (Postdoctoral Researcher 12ZG820N) and Yury Villagrán-Zaccardi (Postdoctoral Researcher Marie Skłodowska-Curie Actions - Seal of Excellence 12ZZD21N) would like to thank the Research Foundation-Flanders (FWOVlaanderen) for the financial support.

The authors greatly appreciate the collaboration of Mrs. Aneeta Mary Joseph and partners from the ASHCEM project, which in itself is a part of the bigger program MaRes aimed at creating and demonstrating an operational, flexible toolbox to recover metals and valorize the residual matrix into building materials funded by SIM (Strategic Initiative Materials in Flanders) and VLAIO (Flanders Innovation \& Entrepreneurship). The provision of PIA and preparation of the some of the analysed concrete mixes is appreciated.

\section{Authorship statement (CRediT)}

Natalia Alderete: Conceptualization, Methodology, Formal analysis, Investigation, Writing - original draft, Funding acquisition. Yury Villagrán-Zaccardi: Conceptualization, Methodology, Writing - review \& editing. Nele De Belie: Supervision, Validation, Writing - review \& editing, Funding acquisition.

\section{References}

[1] J. Kaufmann, W. Studer, One-dimensional water transport in covercrete - application of non-destructive methods. Mater Struct (1995) 28: 115-124. https://doi.org/10.1007/BF02473185

[2] C. Hall, W. Hoff, Water transport in brick, stone and concrete, 2nd ed., CRC Press - Taylor and Francis Group, London, USA, 2009. https://doi.org/10.1520/CCA10518J

[3] D.P. Bentz, M. a Ehlen, C.F. Ferraris, E.J. Garboczi, Sorptivity-based service life predictions for concrete pavements. 7th Int Conf Concr Pavements-Orlando, Florida, USA, Sept. 1 (2001) 9-13. http://citeseerx.ist.psu.edu/viewdoc/download?doi=10.1.1.23.8113 \&amp;rep=rep1\&amp;type=pdf

[4] J. Castro, D. Bentz, J. Weiss, Effect of sample conditioning on the water absorption of concrete. Cem Concr Compos (2011) 33: 805813. https://doi.org/10.1016/j.cemconcomp.2011.05.007

[5] R.P. Spragg, J. Castro, W. Li, M. Pour-Ghaz, P.-T. Huang, J. Weiss, Wetting and drying of concrete using aqueous solutions containing deicing salts. Cem Concr Compos (2011) 33: 535-542. https://doi.org/10.1016/j.cemconcomp.2011.02.009

[6] R. Henkensiefken, J. Castro, D. Bentz, T. Nantung, J. Weiss, Water absorption in internally cured mortar made with water-filled lightweight aggregate. Cem Concr Res (2009) 39: 883-892. https://doi.org/10.1016/j.cemconres.2009.06.009 
[7] C. Hall, A. Hamilton, Beyond the Sorptivity : Definition, Measurement , and Properties of the Secondary Sorptivity. J Mater Civ Eng (2018) 30: 1-7. https://doi.org/10.1061/(ASCE)MT.1943-5533.0002226

[8] J. Cai, B. Yu, M. Zou, L. Luo, Fractal characterization of spontaneous co-current imbibition in porous media. Energy and Fuels (2010) 24: 1860-1867. https://doi.org/10.1021/ef901413p

[9] N.M. Alderete, Y.A.V. Zaccardi, N. De Belie, Mechanism of long-term capillary water uptake in cementitious materials. Cem Concr Compos (2020) 106: 103448. https://doi.org/10.1016/j.cemconcomp.2019.103448

[10] ASTM C 1585, Standard test method for measurement of rate of absorption of water by hydraulic-cement concretes, (2004) 1-6.

[11] Y.A. Villagrán Zaccardi, N.M. Alderete, N. De Belie, Improved model for capillary absorption in cementitious materials: Progress over the fourth root of time. Cem Concr Res (2017) 100: 153-165. https://doi.org/10.1016/j.cemconres.2017.07.003

[12] N.S. Martys, C.F. Ferraris, Capillary transport in mortars and concrete, Cem Concr Res (1997) 27: 747-760. https://doi.org/10.1016/S0008-8846(97)00052-5

[13] Y. Zhifu, Assessing Cumulative Damage in Concrete and Quantifying its Influence on Life Cycle Performance Modeling, Purdue University, 2004. https://doi.org/10.1145/1198467.1198470

[14] N.M. Alderete, Y.A. Villagrán Zaccardi, N. De Belie, Physical evidence of swelling as the cause of anomalous capillary water uptake by cementitious materials. Cem Concr Res (2019) 120: 256-266. https://doi.org/10.1016/j.cemconres.2019.04.001

[15] A. Mary Joseph, R. Snellings, P. Nielsen, S. Matthys, N. De Belie, Pretreatment and utilization of municipal solid waste incineration bottom ashes towards a circular economy. Constr Build Mater (2020) 260: 120485. https://doi.org/10.1016/j.conbuildmat.2020.120485

[16] N.M. Alderete, A. Mary Joseph, P. Van den Heede, S. Matthys, N. De Belie, Effective and sustainable use of municipal solid waste incineration bottom ash in concrete regarding strength and durability. Resour Conserv Recycl (2020) submitted.

[17] N. M. Alderete, A. M. Joseph, P. Van den Heede, S. Matthys, N. De Belie, Effective and sustainable use of municipal solid waste incineration bottom ash in concrete regarding strength and durability. Resour Conserv Recycl, (2021) 105356, in print.

[18] D. Snoeck, L.F. Velasco, A. Mignon, S. Van Vlierberghe, P. Dubruel, P. Lodewyckx, N. De Belie, The influence of different drying techniques on the water sorption properties of cement-based materials. Cem Concr Res (2014) 64: 54-62.

https://doi.org/10.1016/j.cemconres.2014.06.009

[19] J. Zhang, G.W. Scherer, Comparison of methods for arresting hydration of cement. Cem Concr Res (2011) 41: 1024-1036. https://doi.org/10.1016/i.cemconres.2011.06.003

[20] V.S. Ramachandran J.J. Beaudoin, Handbook of Analytical Techniques in Concrete Science and Technology, 1st Edition, 2000.

[21] H. Ma, Mercury intrusion porosimetry in concrete technology: Tips in measurement, pore structure parameter acquisition and application. J Porous Mater (2014) 21: 207-215. https://doi.org/10.1007/s10934-013-9765-4

[22] M. Khanzadeh Moradllo, C. Qiao, H. Hall, M.T. Ley, S.R. Reese, W.J. Weiss, Quantifying fluid filling of the air voids in air entrained concrete using neutron radiography. Cem Concr Compos (2019) 104: 103407. https://doi.org/10.1016/j.cemconcomp.2019.103407

[23] F. Ghasemzadeh, M. Pour-Ghaz, Effect of damage on moisture transport in concrete. J Mater Civ Eng (2015) 27: 1-12. https://doi.org/10.1061/(ASCE)MT.1943-5533.0001211 